\title{
Digital identification in the context of resocialization problems
}

\author{
Olga Savina ${ }^{1, *}$, Madrudin Magomed-Eminov ${ }^{2}$, and Olga Kvasova ${ }^{3}$ \\ ${ }^{1}$ Moscow State University, Department of Psychology, 127434, 4-46 Dubky str., Moscow, Russia \\ ${ }^{2}$ Moscow State University, Department of Psychology, 125009, 2 B. Nikitskaya str., Moscow, Russia \\ ${ }^{3}$ Moscow State University, Department of Psychology, 125009, 8-67 Molodogvardeyskaya srt., \\ Moscow, Russia
}

\begin{abstract}
The paper analyzes modern concepts of identity in connection with the processes of resocialization. Transformations affecting all aspects of modern society lead to a change in the processes of socialization of individuals. In connection with the above-mentioned features of the current situation, attention is focused on the possibilities of effective resocialization aimed at matching a new social situation for the individual or the society as a whole. The emphasis is placed on the value aspects of identity and the consideration of resocialization as a transformation of the personality's value structures under conditions of semantic heterogeneity. It is emphasized that the transformation of identity is the basis and at the same time the result of resocialization. The research methodology included an analysis of adolescents' Internet blogs, a survey of 30 respondents (using a questionnaire, a modified methodology for "Who am I?", methods for diagnosing addictive identity and analyzing pages in social networks). The empirical study shows the difference in teenagers' views of identity in the real and virtual world.
\end{abstract}

\section{Problem statement}

The relevance of the development of ideas about identity in connection with resocialization is associated with the peculiarities of the current situation in science, society and the world as a whole, which is characterized by high dynamism, crisis, extremity, clash of civilizations, cultures, ideology of globalism and cultural diversity [1]. Socialization, traditionally considered as an introduction to life in society, is based on identity $[2,3]$. The concept of resocialization is relatively new for psychological science, its active development was carried out in social philosophy, sociology, political science, law, pedagogical science [4]. In psychology, until recently, the problem of resocialization was associated more with the provision of psychological support in the penitentiary system, in relation to the social situation of people (mainly due to old age and the end of the stage of labor socialization), and as a result of the change of environment (for example, migrants). The term resocialization is interpreted ambiguously, not clearly enough its breeding with the concepts of "cultural renewal", "re-adaptation", "secondary socialization",

* Corresponding author: 220163@mail.ru 
"desocialization", even "acculturation", "rehabilitation". The researchers emphasize the dual nature of resocialization, which manifests itself in the negative (the destruction of the values learned in the course of socialization, behavioral models) and the positive side of this phenomenon (the assignment of new values, roles that are radically different from the previous ones).

At the most superficial level of analysis, there is a "narrow" and "broad" understanding of resocialization. In a broad sense, resocialization is interpreted as socialization in adulthood (which, obviously, can include the need for social adaptation in a variety of relatively new social situations: new work, retraining, change of residence, changes in the family situation, etc.). In a narrower sense, we are talking about socialization in connection with fundamental, significant transformations of the value character, when the former values are unacceptable. The axiological transformation of society, in contrast to the gradual assimilation of the existing norms and rules in this society, represents a qualitatively different change in the structure and dynamics of the value system [5]. It is interesting that modern sociologists point to the attribution of resocialization not only to the processes of secondary (traditional view), but also to primary socialization. This is due to the expansion of the reference group and space-time compression due to the development of digital technologies (the role of the family and the school is no longer exceptional; due to social Internet networks values and behavior of people who are far from us in spatial and temporal sense are internalized [6]. The trends of individualization in primary socialization are revealed, the role of initiative and the ability of an individual to construct behavior, norms, rules based on the construction of his Self and identity increases, and the process of resocialization does not apply only to a certain age or social status of a person, becoming continuous.

In modern humanitarian knowledge it is difficult to name a topic that causes as wide response as the study of identity. The attention of researchers to identity of the individual is explained by the fact that it refracts and highlights the features of modern life and the state of society, including the Russian one [7]. In cultural activity psychology [8], there are two approaches to identity: 1) substantive, structural and morphological, dispositional, with an emphasis on statics, balance, form, structure, system, rationality of the subject; 2). temporal, based on the dynamic-transformational representation, understanding of identity, personality, which emphasizes its fluidity, diversity, non-identity, diversity, nonequilibrium. Dichotomous opposition of "self-determine" ("self-constructing") and fluid, self-deffusive identity involves the person having a binder-discriminating nature. This work of the individual (personality work (M. Magomed-Eminov) that is in Genesis, is a transit operation; and the identity, identity transit identity. With the theoretical positions of subject-existential approach noted the presence of two features of identity as a reflection of the consistency of the systemic organization of the personality with the inclusion of all the spaces of her existence and causality of the identity identification of the Other with respect to itself.

One of the promising directions of studying the relationship of identity with the processes of re-socialization is the study of digital identity associated with the global transformation of the process of cultural and historical development of a person under the influence of new information technologies [9], with the active implementation of information, digital technologies, and the opportunities and dangers that they represent for the [10]. The research conducted in the field of cyberpsychology indicates the changes in the person's ideas about himself in the context of virtual communication and interaction [11]. The personality expands its capabilities for self-design, role-playing experimentation and increasing controlled self-presentations. On the pages of their virtual diaries teenagers and young people use various techniques of self-presentation to create their digital identity [12]. An attractive opportunity of virtual self-management, self-impression, designing an 
attractive image of the world, the production of events and their fixation is created. Along with the above, new trends are developing: real virtuality (a statement of the realities of life that takes place on the Internet), an increase in the requirements for user verification, a change in attitude to virtual identity as "false" [13]. Adolescence is one of the most difficult periods of personality formation, modern adolescents simultaneously exist in two worlds, the real and the virtual. Existence in the virtual world has a significant impact on the real behavior of adolescents, but numerous studies of virtual identity are usually conducted on adult respondents, affecting one of the most problematic groups of the population only partially [14]. That is why, our further research will be devoted to how the construction of identity by teenagers and their existence in virtual reality are connected.

The relevance of the development of ideas about identity in connection with resocialization is associated with the peculiarities of the current situation in science, society and the world as a whole, which is characterized by high dynamism, crisis, extremity, clash of civilizations, cultures, ideology of globalism and cultural diversity. Socialization, traditionally considered as an introduction to life in society, is based on identity. The concept of resocialization is relatively new for psychological science, its active development was carried out in social philosophy, sociology, political science, law, pedagogical science. In psychology, until recently, the problem of resocialization was associated more with the provision of psychological support in the penitentiary system, in relation to the social situation of people (mainly due to old age and the end of the stage of labor socialization), and as a result of the change of environment (for example, migrants). The term resocialization is interpreted ambiguously, not clearly enough its breeding with the concepts of "cultural renewal", "re-adaptation", "secondary socialization", "desocialization", even "acculturation", "rehabilitation". The researchers emphasize the dual nature of resocialization, which manifests itself in the negative (the destruction of the values learned in the course of socialization, behavioral models) and the positive side of this phenomenon (the assignment of new values, roles that are radically different from the previous ones). At the most superficial level of analysis, there is a "narrow" and "broad" understanding of resocialization. In a broad sense, resocialization is interpreted as socialization in adulthood (which, obviously, can include the need for social adaptation in a variety of relatively new social situations: new work, retraining, change of residence, changes in the family situation, etc.) $[15,16,17,18]$. In a narrower sense, we are talking about socialization in connection with fundamental, significant transformations of the value character, when the former values are unacceptable. The axiological transformation of society, in contrast to the gradual assimilation of the existing norms and rules in this society, represents a qualitatively different change in the structure and dynamics of the value system. It is interesting that modern sociologists point to the attribution of resocialization not only to the processes of secondary (traditional view), but also to primary socialization. This is due to the expansion of the reference group and space-time compression due to the development of digital technologies (the role of the family and the school is no longer exceptional; due to social Internet networks values and behavior of people who are far from us in spatial and temporal sense are internalized. The tendencies of individualization in primary socialization are revealed, the role of initiative and the ability of an individual to construct behavior, norms, rules based on the construction of his Self and identity increases, and the process of resocialization does not apply only to a certain age or social status of a person, becoming continuous through the life span.

\section{The purpose and methodology}

The empirical study was aimed at identifying the psychological features of the construction of identity in social networks in adolescents and young adults in connection with 
resocialization (in the case of a fundamental difference between the previous and current value-semantic guidelines).

Object of study: discourses of adolescents 10-19 years old in the pages in social networks, blogs, etc. The process of constructing identity in virtual networks (on the example of social network "in contact" and "LiRu") was studied. The study conducted a content analysis of the Internet pages of diaries, blogs, modified methods of M. Kuhn and T. McPartland "Who am I?" [19] with the subsequent content analysis to explore various aspects of "the Image "I" and the axiological aspects of identity, the technique of diagnostics of addictive identity, developed a questionnaire to identify the various aspects of the relations of the teenager to himself, to others, etc. The study involved adolescents and young men (total 30 people (average age-16.5 years; 20 girls and 10 boys).

\section{Results}

The analysis of three blogs of teenagers showed that there is a difference between the blog of a young man and the blogs of girls in the preference of means of expression (text or graphic representation), but these results can not be extended to a wide sample, because this stage of the study allowed to study in detail the features of the manifestation of identity specifically in these blogs and is an analysis of a particular case. Meaningful analysis showed that assessing their Self in the real world, teenagers see themselves as students (63\%); highlight their positive personal qualities (59\%); features of communication and relationships with others $(55.5 \%)$; Hobbies (48\%): but also negative personal qualities $(33 \%)$, relevance to General categories $(26 \%)$, family roles $(18.5 \%)$. When answering the question "Who am I online?", educational activities were mentioned only $15 \%$ of respondents, and in the first place came the features of communication and relationships with others $(55.5 \%)$, personal positive qualities $(41 \%)$ and interests $(33 \%$, "gamer", "cat lover", "bookworm", etc.). Teenagers ' ideas about how they look in the eyes of virtual interlocutors are concentrated around positive personal qualities $(59 \%$, "interesting with me", "polite", "funny", etc.). Features of communication and relationships play an important role (44\%). Also, there was a new group of answers concerning self-acceptance (33\%, "I'm a cool person", "who I am", "I'm probably not so famous", etc.), equal in frequency to negative personal qualities. The data obtained suggest that there are differences between real and virtual identity. The results of the study show that the sex of the subjects is related to their preferences in the choice of objective/subjective selfcategorizations $(r s=-0.446(p<0.05)$ : girls more often than boys use objective criteria in assessing how they look in the eyes of Internet interlocutors. Two-way correlation $r s=0,452$ (at a significance level of 0,05 ) was found when checking for a connection between the presence of objective categories in the answers to the questions "Who Am I in the real world?" and, "Who am I online?"; significantly related ratio of subjective and objective answers to the question "Who Am I on the Internet?" rs=-0.447 ( $p<0.05)$. The study revealed no significant relationship between addictive identity and teenagers ' ideas about themselves in real life and the Internet space. Thus, the data obtained in our study suggest that there are differences in the views of adolescents between real and virtual identity; demonstrate a contradiction in relation to the importance of learning activities in real and virtual positioning, in the virtual space of the Internet comes to the fore communication and building relationships. Tendencies in the choice of the interlocutor on the Internet are revealed: orientation on communication, on appearance of the person and his page, and also on existence of common interests. 


\section{Discussion}

The transforming world in which modern man lives and acts requires him to constantly define and redefine values and meanings in order to solve life's semantic tasks. Therefore, the process of re-socialization becomes permanent, and is not limited to individual time periods of life, not confined to a specific age. Identity is considered as incomplete, becoming, transforming, transit-as a project, not the final result of socialization. Selfidentity is produced (constructed) in the work of the individual, and on this basis the activity itself is already unfolding. Modern information and digital technologies, on the one hand, create opportunities for the expansion of identity, allow to overcome the space-time, socio-cultural limitations of resocialization; on the other hand, they increase the possibility of marginalization (including manifestations of extremism, violence, risk), especially against adolescents.

This work of the individual that is in Genesis, is a transit operation; and the identity, identity transit identity. With the theoretical positions of subject-existential approach noted the presence of two features of identity as a reflection of the consistency of the systemic organization of the personality with the inclusion of all the spaces of her existence and causality of the identity identification of the Other with respect to itself.

One of the promising directions of studying the relationship of identity with the processes of re - socialization is the study of digital identity associated with the global transformation of the process of cultural and historical development of a person under the influence of new information technologies, with the active implementation of information, digital technologies, and the opportunities and dangers that they represent for the individual. The research conducted in the field of cyberpsychology indicates the changes in the person's ideas about himself in the context of virtual communication and interaction. The personality expands its capabilities for self-design, role-playing experimentation and increasing controlled self-presentations. On the pages of their virtual diaries teenagers and young people use various techniques of self-presentation to create their digital, virtual identity. An attractive opportunity of virtual self-management, self-impression, designing an attractive image of the world, the production of events and their fixation is created. Along with the above, new trends are developing: real virtuality, a statement of the realities of life that takes place on the Internet), an increase in the requirements for user verification, a change in attitude to virtual identity as "false". Adolescence is one of the most difficult periods of personality formation, modern adolescents simultaneously exist in two worlds, the real and the virtual. Existence in the virtual world has a significant impact on the real behavior of adolescents, but numerous studies of virtual identity are usually conducted on adult respondents, affecting one of the most problematic groups of the population only partially. That is why further research will be devoted to the way of identity construction by teenagers and their existence in virtual reality are connected.

\section{Conclusions}

We present the interpretative cultural-historical approach to personality in digital socialization and resocialization. The main idea of it is that the solution of the individual problems of development, adaptation, as well as existential problems, is carried out in the context of continuous resocialization horizon, which is based on the transformation of value and meaning structures of the individual life world [20]. This provision has its practical interpretation, which means that the implementation of any practical tasks - rehabilitation and speaking wider - life tasks should be accompanied by the implementation of a metapractical strategic objective: the transformation of specific social relations of the individual, mediated by cultural and symbolic means, including digital, creating a certain symbolic 
space of human existence. In this case, for example, the answer is not to the question to the psychologist, how much time the child should spend at computer, and the question of how to teach the child healthy and properly, solving certain problems using digital virtual technologies, to interrupt their own activities, their own classes, that is, to manage digital technologies and master their digital behavior.

We see three important components in digital socialization: 1) it is usually emphasizedprojection of qualitative continuum mental processes into discrete spatial numerical forms (that is, forms working on the basis of the use of digital signs expressing numbers, and operations between them, creating computational procedures). These sign digital structures are understood as mediating activity and mental processes, activity and semantic structures of the individual in the social world. 2) the second focus, is formed by the fact that digital operations create a sign-graphic image that simulates on technical devices the image of the world and the way of life of man - the so-called virtual, or simulation, education. In this regard, digital spaces are not discrete-numerical, they simulate the real image of the human world to such an extent that they acquire the status of a special hyper- human reality. 3) the third feature of digital socialization is that the processes of cultural mediation of direct contact between people are replaced by cultural mediation of distant contact: that is, direct social contacts through digital technologies are replaced by double mediation: both the signs themselves mediate, and the relations between people are distantly mediated. Thus, digital resocialization, on the one hand, reduces quality to number (discreteness), on the other hand, creates Hyper - quality-through simulative visualizations, during which the Other becomes a distant cultural artifact.

\section{Application}

Psychological and pedagogical aspects of the implementation of cultural and activity methodology of resocialization. One of the aspects of the modern direction of development of resocialization tasks is its connection with preventive psychology - the ability to predict, prevent negative aspects of socialization of individuals and groups. Currently, there is a need to combine and systematize the results of a variety of multidisciplinary research and experience in relation to the problems of resocialization and prevention of negative aspects of secondary adaptation, as well as the evaluation of information on educational and preventive activities of the actual system of prevention within the framework of psychological knowledge. The analysis is based on the account of individual, personal, socio-psychological and psychological-pedagogical factors of resocialization, in particular, causing social deviations in behavior, taking into account educational and preventive work to prevent these deviations. The creation of psychological support for effective resocialization outcomes is the most important condition for improving the effectiveness of preventive activities. In turn, the problem of improving the effectiveness of early prevention should be addressed in the following main areas: first, timely diagnosis of asocial deviations and social maladjustment of different categories of people in crisis, extreme situations, conditions characterized by a radical change of cultural patterns, traditions, customs, language, religion, etc. (migrants, military personnel who visited combat zones, convicted persons, including minors, persons with different types of dependence, clients of psychological and psychotherapeutic centers, victims of violence and terrorist attacks, young people (at risk, as well as those affected by the ideas of extremism, radicalism, terrorism, destructive cults); secondly, the implementation of a differentiated approach in the choice of technologies of psychological and pedagogical correction of deviant behavior; third, the identification of adverse factors and desocializing influences from the immediate environment, which cause deviations in the development of the individual; fourth, the development of preventive impact programs, including the use of 
distant methods of psychological assistance, online counseling, educational work in social networks, etc. As a unit of deviant behavior can be specific deviations in behavior (for example, vandalism, nationalism, aggressiveness, pugnacity, depression, etc.), its various forms (for example, racketeering, suicidal phenomena, theft, drug addiction, substance abuse, drunkenness, etc.), etc. in preventive psychology can also be used methods of other scientific disciplines: sociological (social diagnostics, collection of sociological information, interviews, factor analysis, questionnaires, etc.).); criminological (criminal statistics, identification, forensic examination, interrogation, Prosecutor's warning, etc.); mathematical (modeling, measurement, scaling, ranking, etc.); medical (collection of medical data, health mapping, diagnostic methods, etc.); pedagogical (pedagogical observation, conversation, study of documentation, study of performance, survey, pedagogical experiment, study and generalization of best and negative experience, historical and pedagogical analysis, etc.).

Asserting the permanent nature of resocialization in the life of modern person, resocialization and psychological helping act as a special form of practice, different from counseling, psychotherapy and other areas of practice, such as the transformation of the human psyche in real situations, in which life activity is carried out and semantic tasks are solved. The modern potential consumer of psychological services is focused not on obtaining abstract academic knowledge in the field of psychology, but on solving actual life problems, including those related to the need for changes, transformations, that is, permanent resocialization. The development of the modern direction of psychological services using a virtual environment is of great importance. At the moment, there are trends: psychologists are professionals, often either do not reflect the specifics of the needs of customers, or do not possess digital technology, so the market of psychological services today is flooded with low-grade practices; the niche of additional education is occupied, in many ways, few professional specialists. As a result, both professional psychologists and psychology in General are discredited.

\section{References}

1. Z. Bauman, Identity in question, pp. 1-12 (Thousand Oaks, 2009)

2. E. H. Erikson, Identity, youth and crisis (Norton, New York, 1968)

3. P. L. Berger, T. Luckmann, The social construction of reality: a treatise on sociology of knowledge (1966)

4. A. Giddens, Modernity and self-identity: self and society in the late modern age (Stanford University Press, Stanford, p. 186, 1991)

5. B. K. Barber, \& J. A. Olsen, Journal of Adolescent Research, 12 (1997) pp. 287-315

6. J. Gackenbach, J. Bown (Ed.), Boundaries of Self and Reality Online (Academic Press, 2017)

7. Galina U. Soldatova, Elena I. Rasskazova, National Psychological Journal, 2 (2016) pp. 50-60

8. M. Magomed-Eminov, Innovative resources of Social psychology: theory, mehtods in Practice, Ed. O.V. Solovyeva, T.G. Stefanenko (Moscow, pp. 97-104, 2017)

9. L. B. Shneider, V. V. Symanyuk, Psikhologicheskie Issledovaniya, 10, 52 (2017) p. 7

10. D. Madell, S. Muncher, Cyberpsychology and Behavior, 7, pp. 359-367 (2004)

11. J. Gavin, Cyberpsychology \& Behavior, 10, 3, pp. 478-481 (2007)

12. J. R. Suler, Psychology of the digital age: humans become electric hardcover (Cambridg Univ. Press, Cambridge, 2015)

13. L. Leung, Cyberpsychology \& Behavior, 10, 2, 205-214 (2007)

14. B. Marcus, P. Machilek, A. Schiitz, Journal of Personal and Social Psychology, 90, 6, pp.1014-1031 (2006) 
15. M. H. Kuhn, T. S. McPartland, American Sociological Review, 19, 1, pp. 68-76 (1954)

16. J. Kroger, Identity development in adolescence and adulthood (Oxford Research Encyclopedias, 2017). DOI:10.1093/acrefore/9780190236557.013.54

17. J. Carlsson, M. Wängqvist, \& A. Frisen, Developmental Psychology, 51, pp. 334-345 (2015)

18. S. Talaifar, W. Swann, Self and identity (Oxford Research Encyclopedias, 2018). DOI:10.1093/acrefore/9780190236557.013.242

19. J. E. Marcia, Journal of Adult Development, 19, pp. 1-20 (2012)

20. M. Magomed-Eminov, Post-traumatic stress disorders as a loss of the meaning of life, pp. 238-250 (Oxford Univ. Press, Oxford, 1997) 